\title{
Factors Influencing in Early Childbearing and Its Consequences on Nutritional Status of Bangladeshi Mothers: Nationally Representative Data
}

\section{Khirujjaman Sumon}

University of Rajshahi

\section{Md. Abu Sayem}

University of Rajshahi

\section{Abu Sayed Md Al Mamun}

University of Rajshahi

\section{Premananda Bharati}

Indian Statistical Institute

\section{Suman Chakrabarty}

Indian Statistical Institute

\section{Md. Abu Taleb}

University of Rajshahi

Md. Golam Hossain ( $\square$ hossain95@yahoo.com )

University of Rajshahi https://orcid.org/0000-0002-3822-5489

\section{Research article}

Keywords: Early childbearing mothers, Nutritional status, Socio-demographic factors, Two-level logistic regression model, Bangladesh

Posted Date: October 1st, 2020

DOI: https://doi.org/10.21203/rs.3.rs-67538/v1

License: (a) (1) This work is licensed under a Creative Commons Attribution 4.0 International License. Read Full License 


\section{Abstract}

Background: Early marriage and early pregnancy is a social as well as medical problem in developing countries, which may have an impact on health and nutritional status of teenage mothers. Therefore, the objective of this study was to determine the influencing factors of early childbearing (ECB) and its consequences on nutritional status of Bangladeshi mothers.

Methods: Data was extracted from the last survey of Bangladesh Demographic and Health Survey (BDHS-2014). Women who delivered their first baby before their age 20 years are considered as ECB mothers. Nutritional status was measured by body mass index (BMI) which was categorized as (i) under nutrition (BMl $18.5 \mathrm{~kg} / \mathrm{m}^{2}$ ), (ii) normal (18.5 $\leq B M \mid<25 \mathrm{~kg} / \mathrm{m}^{2}$ ) and (iii) over nutrition $B M I \geq 25 \mathrm{~kg} / \mathrm{m}^{2}$ ). Chisquare test and both univariable and multivariable logistic regressions, and z-proportional test were used in this study.

Results: This study revealed that the prevalence of ECB among currently non-pregnant mothers in Bangladesh was $83 \%$ (urban: $77 \%$ and rural: $85.8 \%$ ). A multivariable binary logistic regression model provided the following six risk factors of ECB: (i) living location (division), (ii) respondents' education, (iii) husbands' education, (iv) household wealth quintiles, (v) respondents' age at first marriage, and (vi) number of family members. Still $17.6 \%$ mothers were undernourished in Bangladesh; among them $18.5 \%$ and $13.4 \%$ were ECB and non- ECB mothers respectively, while $25.5 \%$ mothers were over nourished. Univariable model demonstrated that ECB mothers had a greater risk to be undernourished than non-ECB mothers [COR=1.26, 95\% Cl: $1.11-1.43 ; p<0.01]$.

Conclusions: In this study, some modifiable factors were found as predictors of ECB in Bangladesh. ECB mothers were more prone to become under-nourished. These findings can be considered to reduce the number of ECB mothers in Bangladesh consequently to improve their nutritional status.

\section{Background}

The women who delivered children before attaining the age of 20 years, old are usually called early childbearing (ECB) mothers [1]. In the last few decades, the practice of early marriage and early pregnancy were common in Bangladesh despite the substantial development in Human Development Index (HDI) [2]. More than 75 percent of the first-born children were born to women before their 20th birthday and mortality rate for those children was 10.4 percent in Bangladesh [3]. It was estimated that more than 50 percent female and 5 percent male adolescents being married before reaching 20 years thus impacts on high maternal, infant and neonatal mortality (322, 52 and 45 per 100,000 live births respectively) was comparatively higher in Bangladesh [4]. The pregnancy rate among adolescents was higher than adult mothers particularly due to their higher fertility rate, poor reproductive knowledge, inexperience and insufficient use of family planning practice and finally inadequate engagement with care providers [5]. In Bangladesh, out of 66.8 percent married adolescents, only 9 percent used contraceptives, compared to married adults (19 percent) [6]. Early pregnant or ECB mothers need extra 
attention to consider their health, babies' growth and development during pregnancy and lactation and for long term consequences [7]. To save lives, to make them healthy and to prevent mortality and morbidity, more attention on nutritional requirements for adolescent mothers is necessary in developing and under-developed countries including Bangladesh [8]. The adolescent mothers with poor health status due to nutritional deficiencies are at higher risk of eclampsia/convulsion, obstruct labor, and hemorrhage during pregnancy and childbirth. Even they are more at risk of pre-term labour, gestational diabetes and hypertension $[9,10]$. The pelvic bone of young mothers may not have fully developed to accommodate the passage of the baby thus increasing the risk of obstructed labour [11]. Along with morbidity, the risk of pregnancy related mortality was 5 to 7 times before the age 15 years and double among 15 to 19 years than adult mothers $[12,13]$. Poverty is the basic cause of nutritional deficiency throughout the world. A study on African-American community in Chicago reported that adolescent mothers were more likely to be unemployed, lived in poverty and depending on social welfare [14]. The cultural, religious, economic and other social factors (i.e. education) also impacts on early pregnancy and nutritional deficiency; even some community create pressure to probe fertility on a still growing body $[15,16,17,18]$. Other studies established that socio-economic factors such education, wealth index, age at marriage, number of everborn children, residence, religion, occupation, place and type of delivery are linked to poor health and nutritional status $[19,20,21,22]$.

The Government of Bangladesh (GOB) achieved some health-related millennium development goals (MDGs) such as reducing child mortality and improving maternal health. Now government is following health related Sustainable Development Goals (SDGs) to achieve integrated targets for 2030 [23]. In spite of considerable progress, Bangladesh still facing trouble with malnutrition that adversely affecting the children and their mother's health, it is increased the risk of deaths, illness and reducing worker productivity that impacts on countries economy. Now Bangladesh is facing dual burden (underweight and overweight) of malnutrition especially among women [23]. It is very difficult to improve policy to overcome dual burden at the same time without identifying the risk factors of the separate problems.

In this study, body mass index (BMI) was used to measure the nutritional status among mothers in Bangladesh. It is enumerated from a person's weight and height. BMI value of less than or equal to $18.5 \mathrm{~kg} / \mathrm{m}^{2}$ is considered as underweight, and this is a general finding among people suffering from chronic energy deficiency [24]. The mean age of marriage for Bangladeshi women was $15.69 \pm 2.97$ years thus increases the risk of being early mothers [25]. Studies reported that the prevalence of underweight $\left(\mathrm{BMI}<18.5 \mathrm{~kg} / \mathrm{m}^{2}\right)$ was higher among poor families in both rural $(38.8 \%)$ and urban $(29.7 \%)$ areas [24, 25]. A study on socio-demographic factors including poverty and BMI was analyzed that increasing trend of $\mathrm{BMI}$ in first 16 years and then decreasing trend among ever married women age 15-49 years in Bangladesh [19].

Recently, one study was done with early childbearing among Bangladeshi mothers using BDHS-2011 dataset. Authors considered only early childbearing mothers and did not compare with non-early childbearing mothers to find the effect of socio-economic and demographic factors on nutritional status 
[1]. It is needed to identify the risk factors of early childbearing and its effect on their nutritional status comparing with non-early childbearing mothers using nationally representative last dataset.

Therefore, the aim of the present study was to determine the factors influencing ECB, in addition we also looked the effect ECB on nutritional status among mothers in Bangladesh.

\section{Research questions}

There are three research questions in this study; these are (i) what is the prevalence of ECB mothers in Bangladesh? (ii) what factors are related to ECB in Bangladesh? (iii) what is the effect of ECB on nutritional status among mothers in Bangladesh? We hope our present study can able to provide the answer of these questions. This study can help our government to reduce the number of ECB mothers, and improve their nutritional status consequently to achieve the goals regarding maternal health under Sustainable Development Goals by 2030.

\section{Methods}

A total number of 15,015 non-pregnant Bangladeshi women aged 15-49 years who had at least one ever born child were recruited for the present study. Data was extracted from the last survey of Bangladesh Demographic and Health Survey 2014 (BDHS-2014). They collected socio-economic, health, anthropometric and lifestyle information from 17,863 Bangladeshi married women age ranged from 15 to 49 years. The data was collected from March 24, 2014 to august 11, 2014. This is a nationally representative survey which covered all administrative divisions of Bangladesh. The sampling technique, survey design, survey instruments, measuring system and quality control have been described elsewhere [23].

\section{Sampling:}

BDHS-2014 utilized two stages stratified cluster sampling for selecting sample from Bangladeshi married women aged 15-49 years. Bangladesh is divided into seven administrative divisions: Dhaka, Chittagong, Barisal, Khulna, Rajshahi, Rangpur and Sylhet, and each division is divided into districts. Each district consists of some upazilas. Each urban area in an upazila is divided into wards, which are further subdivided into mohallas. A rural area in an upazila is divided into union parishads (Ups) and, within Ups, into mouzas and villages. These divisions allow the country as a whole to be separated into rural and urban areas. The survey used a sampling frame from the list of enumeration areas (EAs) of the 2011 Population and Housing Census conducted by Bangladesh Bureau of Statistics (BBS). However, BDHS2014 selected randomly 600 enumeration areas (EAs) which probability proportional to the EA size, with 207 EAs in urban and 393 in rural areas. A complete household listing operation was then carried out in all of the selected EAs to provide a sampling frame for the second-stage selection. In the second stage, a systematic sample of 30 households on average was selected per EA to provide statistically reliable estimates of key demographic and health variables for the country as a whole, for urban and rural areas separately, and for each of the seven divisions. With this design, the survey selected 18,000 residential households, which were expected to result in completed interviews with about 18,000 ever-married 
women. Data from a sample of 17,863 married Bangladeshi women were collected. The data set was checked for outliers by the present authors, some missing values were also detected, and these cases were excluded. Currently pregnant women were also excluded in the present study. After removing outliers, cases with incomplete data and currently pregnant women, the data set was reduced to 15,015 for the analysis in the present study.

\section{Outcome variable:}

Age at childbearing of mothers was considered as first outcome variable in this study, and it was classified into two classes such as (i) early childbearing (ECB) (delivery first baby before age 20; code =1), (ii) non-early childbearing (non-ECB) (delivery first baby after age 20; code $=0$ ) mothers. Nutritional status was the second outcome variable of this study which was measured by body mass index (BMI). BMI was categorized into three categories on the basis of cut-off points; (i) under nutrition (BMl $18.5 \mathrm{~kg} / \mathrm{m}^{2}$ ) (code, 1) (ii) healthy (normal weight) $\left(18.5 \leq \mathrm{BMK}<25 \mathrm{~kg} / \mathrm{m}^{2}\right)$ (code, 2$)$ and (iii) over nutrition $(\mathrm{BMI} \geq 25$ $\left.\mathrm{kg} / \mathrm{m}^{2}\right)($ code, 3) [26].

\section{Independent variables:}

Various socio-economic and demographic factors were used as independent variables such as divisions (living location), place of residence, parents' education level, number of family member, household wealth index, total ever born children and age at first marriage. All selected independent variables with their categories and codes are described in Table 1 (Table 1).

\section{Statistical analysis:}

Frequency distribution was used to determine the prevalence of early childbearing mothers in Bangladesh. Z-proportion test was used to find the difference in each category of nutritional status between ECB and non-ECB mothers. The Chi-square test was used for selecting independent factors for multilevel logistic regression models. In our dataset the observations came from several levels of hierarchy, it was possible to obtain a clustering effect in outcome variable. If having clustering effect, first need to remove it otherwise we could not get actual results, and single-level statistical model would not be appropriate for analyzing this type of data set [27]. Two levels of multiple logistic regression analysis were used to remove the clustering effect for getting the effect of socio-economic and demographic factors on ECB mothers in Bangladesh. To check the existence of clustering effect in outcome variable, we used median odds ratio (MOR). The following formula is used for calculating MOR value:

$M O R=$ where, is the cluster variance. There is no evidence of clustering effect if $M O R=1$, but if $M O R>1$, there is cluster variation of outcome variable [28]. We obtained from our dataset, the MOR=1.372142 >1, there was clustering effect of outcome variable (ECB mothers). We selected two-level binary logistic regression model for analyzing our data. Level I and II were considered for individual and clusters (EAs) levels respectively. In this study the magnitude of the standard error (SE) was used to detect the multicollinearity problem, if the magnitude of the SE less than 0.5 , it was judged that there was no 
evidence of multicollinearity [29]. The goodness of fit of the model was checked by Hosmer and Lemeshow test. Finally, multinomial logistic regression was used to find the effect of early childbearing on nutritional status of Bangladeshi mothers. For statistical analysis of data, sampling weight was necessary but unfortunately proportional allocation technique was not used for selecting samples by BDHS-2014. Sampling weights was calculated for univariate, bivariate and multivariate analysis for this study. Statistical significance was accepted at $p<0.05$. All statistical analyses were performed using SPSS, IBM (version 23.0) and STATA (version 11).

\section{Results}

Out of 15,015 mothers, $83 \%$ were early at childbearing (ECB) stage. The highest number of early childbearing (ECB) mothers (86.0\%) was living in Rangpur division while the lowest number of ECB mothers (77.3\%) was in Sylhet division. The higher number of ECB mothers $(86.1 \%)$ were living in rural area than urban (76.9\%). It was found that $41.8 \%$ ECB mothers were higher educated while $87.3 \%$ and $89.2 \%$ were no and primary educated respectively. $57.6 \%$ higher educated husbands' wives were ECB, while $88.4 \%$ and $89.7 \%$ no and primary educated husbands' wives were ECB respectively. Also, the percentages of ECB mothers were decreasing with increasing their household wealth quintile. ECB mothers married earlier (aged < 18 years) than their counterpart. The number and percentages of ECB mothers were increasing with increasing their number of ever born children. Whereas more number (percentage) of ECB mother (83.75\%) lived in large family (member $\geq 5$ ). Chi-square test demonstrated that all selected variables showed significantly associated with ECB mothers in Bangladesh (Table 2).

The magnitude value of SE for every independent variables in multivariable two-level logistic model were less than 0.50 , there was no evidence of multicollinearity problems among independent variables. After removing the clustering effect of childbearing age, and controlling the effect of other factors on ECB, the two-level model demonstrated that women living in Chittagong [AOR $=1.56,95 \% \mathrm{Cl}: 1.26-1.95 ; p<0.01$ ], Dhaka [AOR = 1.25, 95\% Cl: 1.00-1.54; $p<0.05]$ and Rangpur [AOR = 1.40, 95\% Cl: 1.10-1.77; $<<0.01]$ divisions were 1.56, 1.25 and 1.40 times greater risk to become ECB mothers than women living in Sylhet division respectively. Uneducated [AOR $=1.28,95 \% \mathrm{Cl}: 1.01-1.64 ; \mathrm{p}<0.05]$, primary $[\mathrm{AOR}=2.36,95 \% \mathrm{Cl}$ : 1.97-2.82; $p<0.01]$ and secondary $[A O R=1.99,95 \% \mathrm{Cl}: 1.60-2.48 ; p<0.01]$ educated women were more likely to become ECB mothers compared to higher educated mothers. Women living in poor family had $15 \%$ more likely to become ECB mothers compared to women living in rich family [AOR $=0.85,95 \% \mathrm{Cl}$ : $0.73-0.99 ; p<0.05]$. It was found that women who got married earlier (age $<18$ years) had a 12.58 -fold greater risk to become ECB mothers than their counterpart [AOR $=12.58,95 \% \mathrm{Cl}: 11.23-14.08 ; \mathrm{p}<0.01]$. Uneducated [AOR $=1.95,95 \% \mathrm{Cl}: 1.57-2.41 ; \mathrm{p}<0.01]$, primary [AOR $=2.52,95 \% \mathrm{Cl}: 2.07-3.06 ; \mathrm{p}<0.01]$ and secondary $[A O R=1.80,95 \% \mathrm{Cl}: 1.52-2.12 ; \mathrm{p}<0.01]$ educated husbands' wives had respectively 1.95 , 2.52 and 1.80 times greater risk to become ECB mothers compared to higher educated husbands' wives. It was observed that the AOR was increasing with increasing the number of children; early childbearing mothers had comparatively more ever born children than their counterpart. Women living in a family having 5-7 [AOR = 1.13, 95\% Cl: $1.01-1.27 ; \mathrm{p}<0.01]$ and $\geq 8$ [AOR $=1.29,95 \% \mathrm{Cl}: 1.10-1.52 ; \mathrm{p}<0.01]$ members had a 1.13 and 1.29-fold higher risk to become ECB mothers than women living in 
comparatively small family ( $\leq 4$ members). Hosmer and Lemeshow test (Chi-square value $=9.032, p=$ 0.340 ) showed that our selected model was good fitted to our data (Table 3 ).

The nutritional status among ECB and non- ECB mothers in Bangladesh is presented in Table 4. I was noted that $25.5 \%$ mothers in Bangladesh were over nourished, while $17.6 \%$ mothers were undernourished. Z-proportional test demonstrated that significantly a greater number of ECB mothers (18.5\%) were under nourished than that of non- ECB mothers $(13.4 \%)(p<0.05)$, while the number of over nourished mothers among non- ECB $(33.9 \%)$ was significantly higher than ECB mothers $(23.7 \%)(p<0.01)$. Also it was observed that the number of healthy among ECB mothers (57.8\%) was higher than that of non-ECB mothers $(52.7 \%)(p<0.01)$ (Table 4).

Nutritional status was three categories; (i) under nutrition, (ii) healthy and (iii) over nutrition. It was used as dependent variable; multinomial logistic regression was used to find the effect of ECB on nutritional status. Healthy mothers were considered as reference cases. Both univariable and multivariable multinomial logistic models were used for this purpose. The univariable model demonstrated that ECB mothers had a 1.26 -fold greater risk to be undernourished than non-ECB mothers [COR $=1.26,95 \% \mathrm{Cl}$ : $1.11-1.43 ; p<0.01]$. It was also found that ECB mothers had $36 \%$ higher chance to get normal weight compared to non-ECB mothers [COR $=0.64,95 \% \mathrm{Cl}$ : $0.58-0.70 ; p<0.01]$. Multivariable model showed that ECB mothers were more likely to get normal weight by $12 \%$ than non-ECB mothers [AOR $=0.88,95 \% \mathrm{Cl}$ : $0.78-0.99 ; p<0.05$ ] (Table 5).

\section{Discussion}

Globally around 17 million adolescent girls give birth each year comprising $11.0 \%$ of all births and $90 \%$ occurs in low and middle-income countries. The most prevalent countries are Bangladesh, Brazil, the Democratic Republic of the Congo, Ethiopia, India, Nigeria and the United States [30]. Early pregnancy and adolescent motherhood are still common and deeply embedded in Bangladesh. In this study, we investigated the factors influencing in early childbearing (ECB) among Bangladeshi mothers, because early childbearing causes poor nutritional status among mothers. Though some studies in Bangladesh have examined the effects of socio-economic, demographic and anthropometric factors on nutritional status of early childbearing mothers in Bangladesh, they used BDHS 2007 and 2011 data [1, 2]. In addition, they did not compare with non-ECB mothers. In the present study, we investigated the factors influencing in ECB among Bangladeshi mothers, using Bangladesh Demographic Health Survey data 2014 (BDHS 2014) which was the latest dataset. However, our findings showed that the overall prevalence of ECB among Bangladeshi mothers were 83\% which was slightly lower than previous study (86\%) from BDHS 2011 [1]. The percentage of ECB among mothers has decreased due to increasing the female education and household wealth quintile during the last two decades in Bangladesh and these may the most important reason for the development of ECB [23].

\section{Effect of socio-economic and demographic factors on ECB}


We analyzed the divisional distribution of ECB as regional coverage. The prevalence of ECB mothers were varied among divisions' and the highest number of ECB was observed in Rangpur and lowest in Sylhet division due to differentiation of customs, cultures and economic conditions among the regions $[31,32$, 33]. Therefore, these facts could be potential reasons of ECB. A study in Brazil found a strong association between childbearing at young ages and the mother's subsequent economic and social indicators. Young mothers were less likely to complete high school, less likely to participate in the labour force, more likely to have lower earnings, than women who did not bear children at teenagers [34]. The effect of education may be explained by the likelihood that educated mothers are more able to receive and understand health promotion messages. This study also exhibited that a positive association of mother's education level and ECB. The illiterate were more likely to be ECB than educated mothers. Subsequently, the higher educated mothers were 0.797 times less likely to be ECB than uneducated mothers. This could be depicted as the fact that uneducated mothers were mostly served as housewives with improper knowledge of the effect of early pregnancy. Our results revealed that mothers from rural area were more likely to commence early pregnancy than urban area. Similar results were observed among other south Asian mothers in India and Nepal [8,35]. The other necessary socio-economic characteristics were also considered in this study such as: number of family member, total ever born children, age at first marriage and household wealth quintile [1].

\section{Impact of ECB on nutritional status}

In this study, we found that Bangladeshi mothers had faced dual burden of malnutrition; still more than $17 \%$ mothers were suffering from chronic energy deficiency while $25 \%$ mothers were over nourished. The trends in the number of over nourished mothers in Bangladesh have been increasing but the number of under nourished mothers has been decreasing with increasing the household wealth quintile during the last two decades in Bangladesh [23]. The prevalence of under nutrition among ECB mothers were significantly higher than that of non- ECB mothers. This may indicate the impact of ECB with other mentioned contributing factors. Interestingly, the prevalence of healthy among ECB mothers was also significantly higher than their counterpart may illustrate the optimum utilization of nutrients by young mothers. Alternatively, the prevalence of over nutrition was lower among ECB mothers than non- ECB mothers. This also indicates the imbalance of intake and utilization of nutrients by adult mothers. These results were also supported by the previou study based on Bangladesh Demographic and Health Survey, 2011 [1] and also a cross-sectional study among the nutritional and health risks among adolescent pregnant mothers in Bangladesh [36].

\section{Strength and limitation of the study}

Perhaps, it is the first time to investigate the associated factors of ECB mothers in Bangladesh, and analyze effect of ECB on their nutritional status compared with non-ECB mothers. We analyzed also the risk factors were identified after removing the clustering effect of ECB using by multilevel binary logistic regression analysis. However, there were some limitations of this study. We used secondary crosssectional data derived from BDHS-2014, women's parental related factors were not available such as the 
household wealth quintile of women's parents before their marriage, the education level of parents which were more important predictors for early marriage as well as ECB. Sampling weight was essential to analyze BDHS-2014 data for ensuring national representation of the survey, but in this survey, we did not consider proportional allocation technique for selecting samples from different regions such as divisions. We only controlled the effect of some socio-economic, demographic and anthropometric factors for determining the effect of ECB mothers on their nutritional status, but physiological factors which may also impact on nutritional status such as level of physical activities, level of energy intake and behavior patterns like dietary habits, smoking habits, weight maintenance, methods of weight-loss etc $[37,38]$ due to unavailability of these factors in BDHS-2014 dataset. However, the mentioned factors would be the potential clues to researches to conduct more research on ECB mothers in Bangladesh.

\section{Conclusions}

We investigated the factors of ECB among non-pregnant mothers in Bangladesh aged 15-49 years and compared with non-ECB non-pregnant mothers, in addition the effect of ECB on nutritional status were also observed. Two level and multinomial logistic regression models were applied to find the effect of socio-economic and demographic factors on ECB and the effect of ECB on nutritional status of mothers respectively. The prevalence of ECB mothers in Bangladesh was $83 \%$. It was found that living location (division), respondents and their husbands' education, household wealth quintile, age at first marriage, number of family member was the predictors of ECB among mothers in Bangladesh. Still $17.6 \%$ mothers were suffering from chronic energy deficiency; among them $18.5 \%$ and $13.4 \%$ were ECB and non- ECB mothers respectively. On the other hand, 25.5\% mothers in Bangladesh were over nourished, among them $23.7 \%$ and $33.9 \%$ were ECB and non- ECB mothers respectively. ECB mothers had a higher risk to be underweight than non-ECB mothers. The health authorities of Bangladesh government and nongovernment organization should special attention of childbearing mothers' health and nutritional status due to their potential contribution on the family and productivity. We hope our findings could be considered to reduce the ECB mothers in Bangladesh as well as to improve their nutritional status.

\section{List Of Abbreviations}

AOR

Adjusted odd ratio; BBS:Bangladesh Bureau of Statistics; BDHS:Bangladesh Demographic and Health Survey; BMI:Body mass index; Cl:Confidence interval, COR:Crude odds ratio; EAs:Enumeration areas; GOB:Government of Bangladesh; HDI:Human Development Index; IBM:International Business Machines; MDGs:Millennium development goals; MOR:Median odds ratio; PSU:Primary SamplingUunit; SDGs:Sustainable development goals; SE:Standard error; SPSS:Statistical Package For Social Sciences; STATA:Software for Statistics and Data Science; Ups:Union parishads.

\section{Declarations}


Ethics approval and consent to participate: The 2014 BDHS received ethics approval from the Ministry of Health and Family Welfare, Bangladesh. The 2014 BDHS also received written informed consent for participation in the study was obtained where participants were children (under 16 years old) from their parent or guardian.

Consent for publication: Not applicable for this study.

Availability of data and material: The BDHS-2014 datasets are freely available at https://dhsprogram.com/data/dataset/Bangladesh_Standard-DHS_2014.cfm?flag=0

Competing interests: The authors have no conflict of interests.

Funding: There was no grant, technical or corporate support for this study.

Authors Contributions: KS and MGH conceptualized and designed the research; ASMAM analyzed the data; KS, MAS drafted the original manuscript; MGH, SC, PB, MAT and MAS critically reviewed and edited the manuscript. All the authors read, discussed and approved the final version of the manuscript for publication.

Acknowledgements: The authors would like to acknowledge Bangladesh Demographic and Health Survey (BDHS) and NIPORT for providing the data collected in 2014.

\section{References}

1. Islam A, Islam N, Bharati P, Aik S, Hossain G. Socio-economic and demographic factors influencing nutritional status among early childbearing young mothers in Bangladesh. BMC Women's Health. 2016;16:58.

2. Kamal SMM. Adolescent motherhood in Bangladesh: Evidence from 2007 BDHS data. Can Stud in Popul. 2012;39(1-2):63-82.

3. Maitra P, Pal S. Early Childbirth, Health Inputs and Child Mortality: Recent Evidence from Bangladesh. IZA Discussion Paper Series, No. 2841. 2007; Bonn: Germany.

4. National Institute of Population Research and Training, Bangladesh demographic and health survey Dhaka, Mitra \& Associates and Macro International, Bangladesh and Maryland, USA, 2009.

5. Islam MM, Islam M.K, Hasan MS, Hossain MB. (2017) Adolescent motherhood in Bangladesh: Trends and determinants. PLoS ONE. 2017; 12(11): e0188294.

6. Senanayake P, Ladjali M. Adolescent health: changing needs. International Journal of Gynecology and Obstetrics. 1994; 46(2):137-43.

7. Kominiarek MA, Rajan Nutrition Recommendations in Pregnancy and Lactation. Med Clin North Am. 2016; 100(6): 1199-1215.

8. Goli S, Rammohan A, Singh D. The Effect of Early Marriages and Early Childbearing on Women's Nutritional Status in India. Matern Child Health J. 2015;19(8):1864-80. 
9. Palacios J, Kennedy HP. Reflections of Native American teen mothers. J Obstet Gynecol Neonatal Nurs. 2011;39(4):425-34.

10. Sayem MA, Matin MN, Islam MS, Matubbar MS, Alam MM. The Morbidity Outcomes of Teenage Pregnancy at rural Netrakona in Bangladesh. Int. J Percept. Public Health. 2018;2(3):165-177.

11. Nour NM. Health Consequences of Child Marriage in Africa. Emerg Infect Dis. 2006;12(11):1644-9. PMCID: PMC3372345.

12. United Nations. We the children: end-decade review of the follow-up to the World Summit for Children. Report of the Secretary-General (A/S-27/3). New York: United Nations; 2001.

13. Case Studies. Malaysia Demographic Charact eristic of Adolescents. Adolescent Health Reprodu ctive and Sexual Health Bangkok: UNESCO; 2004.

14. Assini-Meytin LC, Kerry MS, Green M. Long-Term Consequences of Adolescent Parenthood Among African-American Urban Youth: A Propensity Score Matching Approach. J Adolesc Health. 2015;56(5):529-35.

15. Scholl TO, Hediger ML, Salmon RW, Belsky DH, Ances IG. Association between Gynecological Age and Preterm Birth. Pediatric and Perinatal Epidemiology. 1989; 3:357-366.

16. Paranjothy S, Broughton H, Adappa R, Fone D. Teenage Pregnancy: Who Suffers? Archives of Disease in Childhood. 2008;94,239-245.

17. Bacci A, Manhica GM, Machungo F, Bugalho A, Cuttini M. Outcome of Teenage Pregnancy in Maputo, Mozambique. International Journal of Gynaecology \& Obstetrics. 1993;40:19-23.

18. Chen X, Wen SW, Fleming N. Teenage pregnancy and adverse birth outcomes: A large population based retrospective cohort study. International Journal of Epidemiology. 2007;36: 368-373.

19. Khan MM, Krämer A, Khandoker A, Prüfer-Krämer L, Islam A. Trends in socio-demographic and health-related indicators in Bangladesh. 1993-2007: will inequities persist?" Bull World Health Organ. 2011;89:583-93.

20. Hossain MG, Bharati P, Aik S, Lestrel PE, Abeer A, Kamarul T. Body mass index of married Bangladeshi women: trends and association with socio-demographic factors. J Biosoc Sci. 2012;44(4):385-99.

21. Subramanian SV, Perkins JM, Khan KT. Do burdens of underweight and overweight coexist among lower socioeconomic groups in India? Am J Clin Nutr. 2009;90(2):369-76.

22. Bharati S, Pal M, Bhattacharya BN, Bharati P. Prevalence and causes of chronic energy deficiency and obesity in Indian women. Hum Biol. 2007;79(4):395-412.

23. Bangladesh Demographic and Health Survey 2014, National Institute of Population Research and Training, Dhaka; Mitra \& Associates and ORC Marco, Bangladesh and Calvertion, MD,USA. 2014.

24. Gnudi S, Sitta E, Lisi L. Relationship of body mass index with main limb fragility fractures in postmenopausal women. J Bone Miner Res. 2009; 27(4):479-84.

25. Hossain MG, Mahumud RA, Aik S. Prevalence of child marriage among Bangladeshi women and trend of change over time. J Biosoc Sci. 2016; 48 (4): 530-8. 
26. World Health Organization. Diet, Nutrition and the prevention of Chronic diseases, vol. 916. Geneva: Report of a Joint WHO/FAO Expert Consultation; 2003.

27. Khan MHR, Shaw JEH. Multilevel logistic regression analysis applied to binary contraceptive prevalence data. J Data Sci. 2011; 9:93-110.

28. Larsen K, Merlo J. Appropriate assessment of neighborhood effects on individual health: integrating random and fixed effects in multilevel logistic regression. Am J Epidemiol. 2005; 161(1):81-8.

29. Chan YH. Biostatistics 202: logistic regression analysis. Singapore Med J. 2004; 45(4):149-153.

30. World Health Organization. Adolescent pregnancy:WHO factsheet 2014. 2017. Available at: http://www. who.int/mediacentre/ factsheets/ fs364/en/.

31. Geronimus AT. Teenage childbearing as cultural prism. British Medical Bulletin. 2004; 69: 155-166.

32. Kramer KL, LancasterTeen motherhood in cross-cultural perspective.Annals of Human Biology. 2010; 37(5): 613-628.

33. Hoffman SD. Teen Childbearing and Economics: A Short History of a 25-Year Research Love Affair. Societies 2015; 5: 646-663.

34. Narita R, Diaz MDM. Teenage motherhood, education, and labor market outcomes of the mother: Evidence from Brazilian data. EconomiA. 2016;17:238-252.

35. Choe MK, Thapa S, Achmad S. Early marriage and childbearing in Indonesia and Nepal. East-West Center Working Papers, Population Series. 2001:108-115.

36. Nguyen PH, Sanghvi T, Tran LM, Afsana K, Mahmud Z, Aktar B, et al. The nutrition and health risks faced by pregnant adolescents: Insights from a cross-sectional study in Bangladesh. PLoS ONE. 2017; 12(6): e0178878.

37. Najat Y, Alice A, Abbass A, Rizk S. Eating habits and obesity among Lebanese university students. Nutr J. 2008; 7: 32.

38. Cilliers J, Senekal M, Kunneke E. The association between the body mass index of First year female university students and their weight-related perceptions and practices, psychological health, physical activity and other physical health indicators. Public HealthNutr. 2006;9(2):234-43.

\section{Tables}


Table 1

Independent variables with their categories and codes

\begin{tabular}{|c|c|c|c|c|c|}
\hline Variable & Categories & $\begin{array}{l}\text { Code } \\
\text { No }\end{array}$ & Variable & Categories & $\begin{array}{l}\text { Code } \\
\text { No }\end{array}$ \\
\hline \multirow[t]{7}{*}{ Division (living location) } & Barisal & 1 & \multirow[t]{2}{*}{ Place of residence } & Urban & 1 \\
\hline & Chittagong & 2 & & Rural & 2 \\
\hline & Dhaka & 3 & \multirow[t]{2}{*}{ Age at first marriage } & $<18$ years & 1 \\
\hline & Khulna & 4 & & $18 \geq$ years & 2 \\
\hline & Rajshahi & 5 & \multirow{3}{*}{$\begin{array}{l}\text { Household wealth } \\
\text { index }\end{array}$} & Poor & 1 \\
\hline & Rangpur & 6 & & Middle & 2 \\
\hline & Sylhet & 7 & & Rich & 3 \\
\hline \multirow[t]{4}{*}{$\begin{array}{l}\text { Respondents' educational } \\
\text { level }\end{array}$} & $\begin{array}{l}\text { No } \\
\text { education }\end{array}$ & 0 & \multirow[t]{4}{*}{$\begin{array}{l}\text { Husbands' education } \\
\text { level }\end{array}$} & $\begin{array}{l}\text { No } \\
\text { education }\end{array}$ & 0 \\
\hline & Primary & 1 & & Primary & 1 \\
\hline & Secondary & 2 & & Secondary & 2 \\
\hline & Higher & 3 & & Higher & 3 \\
\hline \multirow[t]{3}{*}{ Total ever born children } & $\begin{array}{l}\leq 2 \\
\text { children }\end{array}$ & 1 & \multirow[t]{3}{*}{$\begin{array}{l}\text { Number of family } \\
\text { member }\end{array}$} & $\begin{array}{l}\leq 4 \\
\text { member }\end{array}$ & 1 \\
\hline & $\begin{array}{l}3-4 \\
\text { children }\end{array}$ & 2 & & $\begin{array}{l}5-7 \\
\text { member }\end{array}$ & 2 \\
\hline & $\begin{array}{l}\geq 5 \\
\text { children }\end{array}$ & 3 & & $\begin{array}{l}\geq 8 \\
\text { member }\end{array}$ & 3 \\
\hline
\end{tabular}


Table 2

Association between early childbearing (ECB) and household and other characteristics of mothers in Bangladesh

\begin{tabular}{|c|c|c|c|c|}
\hline Characteristics & Categories & ECB mothers, $\mathrm{N}(\%)$ & $\chi^{2}$-value & p-value \\
\hline \multirow[t]{7}{*}{ Division (living location) } & Barisal & $1502(83.7)$ & \multirow[t]{7}{*}{70.31} & \multirow[t]{7}{*}{$\mathrm{p}<0.01$} \\
\hline & Chittagong & $2022(83.9)$ & & \\
\hline & Dhaka & $2084(80.7)$ & & \\
\hline & Khulna & $1836(84.4)$ & & \\
\hline & Rajshahi & $1812(84.2)$ & & \\
\hline & Rangpur & $1864(86.0)$ & & \\
\hline & Sylhet & $1342(77.3)$ & & \\
\hline \multirow[t]{2}{*}{ Place of residence } & Urban & $3882(76.9)$ & \multirow[t]{2}{*}{203.40} & \multirow[t]{2}{*}{$\mathrm{p}<0.01$} \\
\hline & Rural & $8580(86.1)$ & & \\
\hline \multirow[t]{4}{*}{ Respondents' educational level } & No education & $3108(87.3)$ & \multirow[t]{7}{*}{1724.35} & \multirow[t]{7}{*}{$p<0.01$} \\
\hline & Primary & $4058(89.2)$ & & \\
\hline & Secondary & $4758(84.7)$ & & \\
\hline & Higher & $538(41.8)$ & & \\
\hline \multirow[t]{3}{*}{ Household wealth index } & Poor & $5010(88.9)$ & & \\
\hline & Middle & $2675(87.5)$ & & \\
\hline & Rich & $4777(75.6)$ & & \\
\hline \multirow[t]{2}{*}{ Age at first marriage } & $<18$ years & $10893(93.4)$ & \multirow[t]{2}{*}{3990.98} & \multirow[t]{2}{*}{$p<0.01$} \\
\hline & $18 \geq$ years & $1569(88.4)$ & & \\
\hline \multirow[t]{4}{*}{ Husbands' educational level } & No education & $3842(88.4)$ & \multirow[t]{4}{*}{1204.04} & \multirow[t]{4}{*}{$p<0.01$} \\
\hline & Primary & $3796(89.7)$ & & \\
\hline & Secondary & $3595(83.6)$ & & \\
\hline & Higher & $1229(57.6)$ & & \\
\hline \multirow[t]{3}{*}{ Total ever born children } & $\leq 2$ children & $6346(77.8)$ & \multirow[t]{3}{*}{348.12} & \multirow[t]{3}{*}{$p<0.01$} \\
\hline & 3-4 children & $4300(88.3)$ & & \\
\hline & $\geq 5$ children & $1816(91.3)$ & & \\
\hline
\end{tabular}




\begin{tabular}{|lllll|}
\hline Characteristics & Categories & ECB mothers, $\mathbf{N}(\%)$ & $\chi^{2}$-value & p-value \\
\hline Number of family member & $\leq 4$ member & $5102(81.5)$ & 18.73 & $p<0.01$ \\
& $5-7$ member & $5478(84.4)$ & \\
\hline & $\geq 8$ member & $1882(83.1)$ \\
\hline
\end{tabular}


Table 3

Effects of demographic and socioeconomic factors on early childbearing among mothers in Bangladesh

Variable

SE

p-value
AOR

Lower

Division (living location)

Chittagong Vs Sylhet ${ }^{R}$

0.17

0.001

0.14

0.040

0.14

0.130

0.14

0.205

0.17

0.005

0.15

0.153

1.19

1.56

1.26

1.95

1.25

1.20

1.16

1.40

1.00

1.54

Rangpur Vs Sylhet ${ }^{R}$

Barisal Vs Sylhet ${ }^{R}$

Place of residence

Rural Vs Urban ${ }^{R}$

Respondents' education level

No education Vs Higher ${ }^{R}$

0.15

0.039

1.28

1.01

1.64

Primary Vs Higher ${ }^{\mathrm{R}}$

0.22

0.001

0.21

0.001

2.36

1.97

2.82

Secondary Vs Higher ${ }^{R}$

Household wealth index

Middle Vs Poor ${ }^{R}$

0.09

0.580

1.05

0.89

1.60

2.48

Rich Vs Poor ${ }^{R}$

0.07

0.040

0.85

0.73

1.23

Age at first marriage (Year)

$<18 \mathrm{Vs} \geq 18^{\mathrm{R}}$

0.43

0.001

12.58

11.23

14.08

Husbands' educational level

No education Vs Higher $^{R}$

Primary Vs Higher ${ }^{R}$

N.B.: B-Coefficients, SE-Standard error, Cl-Confidence interval, AOR-Adjusted odd ratio, R-Reference case. 


\begin{tabular}{|c|c|c|c|c|c|}
\hline \multirow[t]{2}{*}{ Variable } & \multirow[t]{2}{*}{ SE } & \multirow[t]{2}{*}{ p-value } & \multirow[t]{2}{*}{ AOR } & \multicolumn{2}{|c|}{$95 \% \mathrm{Cl}$ of $\mathrm{AOR}$} \\
\hline & & & & Lower & Upper \\
\hline Secondary Vs Higher ${ }^{R}$ & 0.15 & 0.001 & 1.80 & 1.52 & 2.12 \\
\hline \multicolumn{6}{|l|}{ Total ever born children } \\
\hline $3-4$ children $V s \leq 2$ children $^{R}$ & 0.10 & 0.001 & 1.53 & 1.34 & 1.74 \\
\hline$\geq 5$ children $V s \leq 2$ children ${ }^{R}$ & 0.18 & 0.001 & 1.71 & 1.40 & 2.10 \\
\hline \multicolumn{6}{|l|}{ Number of family member } \\
\hline 5-7 member $\vee s \leq 4$ member $^{R}$ & 0.07 & 0.040 & 1.13 & 1.01 & 1.27 \\
\hline$\geq 8$ member $V s \leq 4$ member $^{R}$ & 0.10 & 0.002 & 1.29 & 1.10 & 1.52 \\
\hline Goodness of Fit & \multicolumn{5}{|c|}{ Hosmer and Lemeshow test, $\chi^{2}$-value $=9.032, p=0.340$} \\
\hline
\end{tabular}

Table 4

The prevalence of nutritional status among early and non-early childbearing mothers in Bangladesh

\begin{tabular}{|lllll|}
\hline Nutritional status, N(\%) & ECB mothers, N (\%) & Non- ECB mothers, N (\%) & Z-value & p-value \\
\hline Under nutrition, 2643(17.6) & $2301(18.5)$ & $342(13.4)$ & 2.2986 & 0.0214 \\
\hline Normal (healthy), 8543(56.9) & $7198(57.8)$ & $1345(52.7)$ & 3.4678 & $\mathrm{p}<0.01$ \\
\hline Over nutrition, 3829(25.5) & $2963(23.7)$ & $866(33.9)$ & -6.0192 & $\mathrm{p}<0.01$ \\
\hline Total & 12462 & 2553 & & \\
\hline N.B.: ECB: Early childbearing. & & & & \\
\hline
\end{tabular}


Table 5

Effect of early childbearing on nutritional status of mothers in Bangladesh

\begin{tabular}{|c|c|c|c|c|c|c|c|c|}
\hline \multirow[t]{2}{*}{ Nutritional status } & \multirow[t]{2}{*}{ COR } & \multicolumn{2}{|c|}{$\operatorname{COR}(95 \% \mathrm{Cl})$} & \multirow[t]{2}{*}{ p-value } & \multirow[t]{2}{*}{$\mathrm{AOR}^{\mathbb{Q W}}$} & \multicolumn{2}{|c|}{ AOR (95\% Cl) } & \multirow[t]{2}{*}{ p-value } \\
\hline & & Lower & Upper & & & Lower & Upper & \\
\hline $\begin{array}{l}\text { Under nutrition } \\
\text { Vs Normal }\end{array}$ & 1.26 & 1.11 & 1.43 & $p<0.01$ & 1.21 & 0.96 & 1.30 & 0.14 \\
\hline $\begin{array}{l}\text { Over nutrition } \\
\text { Vs Normal }^{R}\end{array}$ & 0.64 & 0.58 & 0.70 & $p<0.01$ & 0.88 & 0.78 & 0.99 & 0.04 \\
\hline
\end{tabular}

